\title{
Multiprovider and Patient Perspectives on Conveying Diagnostic Imaging Investigation Results in a South African Public Health Care
}

\author{
Chandra R. Makanjee, $\mathrm{PhD}^{\mathrm{a}^{*}}$, Anne-Marie Bergh, $\mathrm{PhD}^{\mathrm{b}}$ and Willem A. Hoffmann, $\mathrm{DEd}^{\mathrm{c}}$ \\ ${ }^{a}$ Department of Radiography, University of Pretoria, Pretoria, South Africa \\ ${ }^{\mathrm{b}}$ MRC Unit for Maternal and Infant Health Care Strategies, University of Pretoria, Pretoria, South Africa \\ ${ }^{\mathrm{c}}$ Department of Biomedical Sciences, Tshwane University of Technology, Pretoria, South Africa
}

\begin{abstract}
Introduction

This study explored interaction processes in conveying messages about the results of diagnostic imaging investigations in a public hospital complex in South Africa from the perspective of health care providers and patients.
\end{abstract}

\section{Methods}

The study was part of a qualitative inquiry into the interaction and communication processes relating to diagnostic imaging investigations in the public health care system. Data collection included individual interviews with 24 patients and 62 health care providers (ie, medical practitioners, specialists, radiologists, registrars, radiographers, and nurses). In addition, 12 focus group interviews were conducted with health care providers. The transcribed data were coded and analysed to identify categories and themes.

\section{Results}

Three main themes emerged from the study. The first theme deals with the medical territory, specifically who should interpret and convey the diagnostic results to the patient. The second theme highlights the role of radiographers and nurses in communicating parts of the diagnostic results. The last theme focuses on patient experience, interpretation, and comprehension in the provider-patient communication process.

\section{Conclusions}

The findings provide a multidimensional view about the disclosure of imaging results to patients by medical and nonmedical health care providers. Further research is needed on the role of nonmedical providers in the context of ethical and moral obligation toward patients and the professional restrictions inherent in their scope of practice.

\section{Resumè}

But

Cette étude explore les processus d'interaction dans la transmission des messages concernant les résultats des examens d'imagerie diagnostique dans un complexe hospitalier public d'Afrique du Sud, du point de vue des fournisseurs de soins de santé et de celui des patients. 


\section{Méthodologie}

L'étude s'inscrivait dans le cadre d'une enquête qualitative sur processus d'interaction et de communication concernant les résultats des examens d'imagerie diagnostique dans le système de santé public. La collecte de données s'est faite par des entrevues auprès de 24 patients et de 62 professionnels de la santé (médecins, spécialistes, radiologistes, registraires, radiographes et infirmières). De plus, 12 entrevues sous forme de groupes de discussion ont été réalisées avec des professionnels de la santé. Les données transcrites ont été codées et analysées afin de définir des catégories et des thèmes.

\section{Constats}

Trois thèmes principaux ont émergé de l'étude. Le premier porte sur le territoire médical, à savoir qui doit interpréter et transmettre le message concernant les résultats diagnostiques au patient. Le deuxième thème met en lumière le rôle des radiographes et des infirmières dans la communication d'une partie des résultats diagnostiques. Le dernier thème met l'accent sur l'expérience du patient, l'interprétation et la compréhension dans le processus de communication entre les professionnels de la santé et les patients.

\section{Conclusion}

Les constats de l'étude fournissent une perspective multidimensionnelle sur la divulgation des résultats d'imagerie aux patients par les médecins et les professionnels de la santé autres que les médecins. D'autres recherches seront nécessaires sur le rôle des professionnels autres que les médecins dans le contexte des obligations éthiques et modales à l'endroit des patients et sur les restrictions inhérentes à leur champ d'exercice.

\section{Introduction}

In the diagnostic imaging context, the written radiologic report is the main medium of communication to patients and medical practitioners 123 . However, Bazzocchi [3] contends "that written communication cannot be considered sufficient and that verbal communication will become increasingly central to the development of the modern radiologist" (p. 340). Equally important is the collective responsibility of the radiologist and the referring clinician for the eventual diagnosis [4]. The shift to shared responsibility for communicating results so that findings are not lost "in ether" (p. 854) [4] is controversial [5] because of arguments related to the organization of work and ethical, medicolegal, and training implications [3 67 7] . Mathers et al [8] call for the use of modern communication methods in a "multiprofessional, multi-departmental approach to provide timely effective standardised and seamless results giving service for all" (p. 162). Similarly, Smith and Gunderman [9] pose the question whether radiology department personnel (ie, radiologists, nurses, radiographers, and administrative staff) should provide diagnostic imaging study results to patients or their families. Other scholars focus on the negative communication impact of outsourcing communication responsibilities to parties outside the medical profession, which could be a potential source of error and misunderstanding [10] .

The roles of radiographers, often referred to as radiologic technologists [11], have significantly changed and diversified in response to advances in radiographic technology, skill shortages, and changes in health systems. Generally, radiographers are not allowed to discuss the results of imaging investigations with patients, which often leads to added anxiety 
for patients [8] . In contrast, nurses are allowed to disclose positive results to patients on instruction by medical practitioners when a clinical action is required, such as notifying the patient to make a return consultation appointment [12] . Despite the ideal placement of radiographers and nurses to communicate and sometimes interpret the results of an investigation, the issue of their respective competencies and skills to perform these tasks still needs to be adequately addressed [8] .

From a patient perspective, the timeliness for giving and receiving results is important [3 5 7] . Of equal importance are health professionals' expectations of who should normally communicate the results to the patient and what the patient's preference in terms of where, when, and by whom the results should be conveyed. Studies by Mathers et al [8] and Pahade et al [13] found that patients preferred to be immediately informed of the diagnostic imaging examination results by the radiologist instead of the referring clinician. However, Berlin [14] cautions that the decision to immediately communicate results to the patient should be made on a case by case basis.

Health professionals in the public health sector in South Africa are also confronted with similar issues regarding who should communicate what kind of diagnostic imaging results to patients. A patient who presents at a public health care facility will be referred to the radiology department for necessary investigations. Upon completion of the diagnostic imaging procedure, the radiologist is required to write a radiologic report and return the findings to the referring medical practitioner or specialist, who will then communicate the results to the patient [15]. How long it takes for each patient to receive the results from the medical provider depends on the workload of the radiologist and access to the picture archiving and communication system or a teleradiology system.

The aim of our study was to explore the interaction processes in conveying the results of diagnostic imaging investigations from a multiprovider and patient perspective in a public hospital complex in South Africa, and to understand to what extent this represents the "seamless results" proposed by Mathers et al [8] . This study is one of the first to focus not only on one particular point of contact between the patient and a health care provider, but also on the interactions and communication in the natural setting between patients and providers and between different providers in the continuum of patient care that includes diagnostic imaging investigations, from admission to discharge.

\section{Methods}

This study entailed a qualitative research inquiry using a constructivist approach to explore processes and interactions between multiple health care professionals and patients referred for diagnostic imaging investigations in a multilevel public health care setting that included a district and an academic hospital. Patients admitted to this hospital complex are mainly from poorer communities. Most do not have medical insurance or their insurance is depleted. Their first language is any one of the 11 official South African languages or a language spoken in other southern, eastern, or central African countries. Most have a basic ability to understand English.

Permission for conducting the study was obtained from the Research Ethics Committee of the Faculty of Health Sciences, University of Pretoria, Pretoria, South Africa. All participants were ensured of confidentiality and gave written informed consent before being included. 
The study consisted of two main phases. Phase 1 entailed following ("shadowing") a convenience sample of 24 patients throughout their hospital encounter. Data collection activities included the following:

- Semistructured individual patient interviews conducted on three occasions: at the point of entry, after the imaging investigation, and at the point of discharge from hospital or admission for in-hospital treatment

- Observations of patient-provider and provider-provider interactions at all points of contact by means of observation checklists with closed and openended items

- Collection of radiologic reports and review of medical files

- Individual interviews with 62 health care providers responsible for treating the patient participants ( Table 1 )

Table 1

Study Participants

$\begin{array}{lll} & \text { Phase 1 Phase 2 } \\ \text { Patients } & 24 & - \\ \text { Health care providers } & & \\ \text { Medical practitioners and family physicians } & 20 & 13 \\ \text { Other specialists and registrars } & 4 & - \\ \text { Radiologists and radiology registrars } & 17 & 8 \\ \text { Radiographers } & 18 & 15 \\ \text { Nurses } & 3 & 17 \\ \text { Total } & 62 & 53\end{array}$

Because it was not predictable which patients would present with what condition(s) or which patients would be referred for a diagnostic imaging investigation(s), only willing participants were enrolled when they reported to the casualty department or outpatient department of the district hospital. The shadowing of patients continued until data saturation was reached.

For phase 2, 12 focus group interviews were conducted with 53 purposefully selected health professionals from the various health care provider categories ( Table 1 ); some had participated in phase 1, whereas others did not. Three focus groups were conducted with medical practitioners and family physicians (range: 2-6 per group), three with radiographers (range: 4-6 per group), two with radiology consultants and radiology registrars (residents) (4 in each group), and four with nurses (range: $2-8$ per group).

The transcribed interview and focus group data were manually analysed using an inductive approach after repeated readings of the transcripts; categories were coded and higher-level themes identified [16] . Trustworthiness was enhanced by means of an audit trail and triangulation of data collection methods (ie, observations, individual interviews, and focus groups) [16] . Two researchers first performed independent analysis of the data; thereafter, all three researchers contributed to the refinement of themes and interpretations. 


\section{Findings}

The findings of our study provide perspectives from medical and nonmedical providers on the value of conveying the results of diagnostic imaging investigations, and also focus on patient perspectives. Three main themes emerged from the study: (1) medical territory, specifically regarding who should interpret and convey the diagnostic results message to the patient; (2) the role of radiographers and nurses in communicating parts of the diagnostic results; and (3) patient experience, interpretation, and comprehension in the provider-patient communication process.

The following analysis codes are used in this section to present the authentic voices of the participants: $\mathrm{FG}=$ focus group, $\mathrm{II}=$ individual interview, $\mathrm{PI}=$ patient interview, $\mathrm{MP}=$ medical practitioner or family physician, $\mathrm{RADL}=$ radiologist or a radiology registrar, $\mathrm{RAD}=$ radiographer, and $\mathrm{NP}=$ nurse .

\section{Theme 1: Medical Territory-Who Should "Put the Picture Together"? Who Should Show the Pictures? Who Should Break the Bad News?}

A salient theme in the study was who should take the primary responsibility of conveying messages of imaging investigation results to patients. Most medical practitioners (including family physicians), radiographers, radiology registrars, and radiology consultants expressed strong viewpoints about the control of the final diagnosis - "The final diagnosis, I think that is the role of the clinician" (FGMP).

"The referring clinician has to have a look at the films as well and I think it's at that point that the patient should be shown the images ... At the end of the day, that is the doctor that is going to be treating them, not us [radiologists]" (FGRADL).

In support of this view, medical practitioners further justified the reason for insisting that they should communicate the diagnosis instead of the radiologist by delineating the professional boundary of the radiologist as carrying out the imaging investigation only.

"We [medical practitioners] have the bigger picture - the blood results, the urine results. We can put the picture together ... not just isolating and treating just per investigation. We spend time with the patient. We have a patient relationship. So it's not fair for the investigator [radiologist] to explain the results" (FGMP).

One medical practitioner described the patient-interaction role of the radiologist as being confined to technological interpretation-related matters "to get a better picture, better view, [or] another, that is fine ... that small interaction" (FGMP). In addition, the medical practitioners indicated that the radiologist should merely " ... have a discussion with the patient as to interpret the X-rays better ... give [patients] the report and [tell them] 'Go back to your attending doctor"' (FGMP).

"I can just imagine the radiologist scream, 'You have got lung cancer!' Next one, 'Sorry, my friend, you've got one big lump in the breast'; next one, brain cancer. I do not want my surgeon to be the guy who wanted to read his psychiatry ... I won't allow the bravest surgeon to cut out and take out the problem, so I want that. That is why certain people are attracted to certain things" (FGMP). 
"So let the family physician give him the bad news because he is trained for that and let the radiologist give you the correct diagnosis with the report on a central system" (FGMP).

The radiologists and radiology registrars were of the opinion that it would be unfair and/or inappropriate to make the communication of results their responsibility because their radiologic findings may be inconclusive as a result of the broad spectrum of possible diagnoses.

"Having an inadequate history and inadequate request and not having a doctor's contact number, so to make that our role to discuss what we saw on an x-ray to the patient is inappropriate. Because we don't have all that information, and a lot of the times what we see on an x-ray, we have to give a differential diagnosis for, which ranges from general cancer to a minor infection. So although it's sometimes ... of benefit for showing the x-rays to patients, I think it's better that the referring clinician treating the patient be the one to discuss those findings" (FGRADL).

"Firstly, in terms of the history, often we don't get a good history from the referring clinicians. Sometimes the history is not appropriate or it doesn't help us to come to a specific diagnosis. A lot of things are left out. Often biochemical results are left out; things that we think are important. Sometimes they don't understand what we need and vice versa" (FGRADL).

Another reason for limiting the communication of diagnostic results to the referring medical practitioner was the radiologists' acknowledgement that they often do not have the full picture of the interactions that had taken place before the referral. As such, they were respectful of the doctor-patient trust relationship.

"It's also difficult because you don't know what your referring clinician has told the patient before they sent the patient to you. So sometimes you prefer to have the referring clinician read the report, you know, before you give the information to the patient. Because it's a very general source of problems and conflict between the patients and the referring clinician" (FGRADL).

"I think it might be unfair to make it ours, because we don't see the patient. We don't have the continuity of care and we can't just give them the shocking news or something bad and expect them just to go away and you know we can't follow up on that. It's a bit of a grey area that still need a bit of attention" (FGRADL).

Despite the strong views expressed about the patient-communication boundaries between medical practitioners and radiologists, some clinicians at the district hospital actually expressed some ambivalence regarding the strict professional communication boundaries.

"You see from our [medical practitioner] point of view, I mean, if we tell the patient the results or the radiologist does, it doesn't really make a difference. That's fine, provided we have the [radiological] report. I mean from the patient's point of view, it's really poor that the radiologist can't be bothered to tell what's wrong with him. I mean . . they're doctors first and radiologists second; that patient is their responsibility surely" (FGMP). 


\section{Theme 2: Everybody's Territory—When to Convey What and to Whom?}

Professional participants in this study had diverse views on what could be communicated to patients by other health care providers like radiographers and nurses. The medical providers and radiographers regarded the main communication role of radiographers as preventing harm through judicious interaction with patients and to avoid further harm when patients were unaware of their medical condition. Nurses regarded their own communication role as explaining the diagnostic results already shared by the referring clinician in cases of patient confusion or uncertainty.

However, some medical practitioners were unsure what radiographers were allowed to convey to patients.

"If a patient has an ankle fracture, are [radiographers] allowed to tell the patient, 'You have a fracture'?" (FGMP).

Several practitioners were of the opinion that radiographers "work with it daily for many, many years, surely ... [they] immediately see the fracture" (FGMP).

Although radiographers had the required skill and expertise to communicate certain conditions to patients, communication had to be done with due respect for professional boundaries.

"I think the function of the radiographer [after taking the $\mathrm{x}$-ray is to] just give a little bit information to the patient. 'The findings, we have done the x-rays, we find 1-2-3 according to your x-ray when we look at the picture. That 1-2-3 the doctors must solve.' It will be much better to the patient because the doctor doesn't explain anything to the patient about the $\mathrm{x}$ rays" (FGNP).

"Usually if a patient comes in with a suspected fracture, I don't know because even the radiographers don't say anything. They just send back the patients. They might tell the patient that the doctor will have a look and explain" (FGNP).

Generally, radiographers agreed that it was appropriate not to cross professional boundaries because the communication of diagnostic results did not fall within their scope of practice.

"They ask me very often to show [the x-ray] but we are not allowed to discuss with them. So I usually tell them the x-rays will be on the system now for their doctor to see it and then he will discuss it with them as soon as he sees it on the computer" (IIRAD).

However, there was an ethical dilemma.

"In some circumstances it's good to tell them, but in other circumstances it's not" (FGRAD).

As such, radiographers occasionally shared some diagnostic information with the patient with the sole purpose of avoiding further harm to the affected body part during the transition back to the referring clinician for further medical care.

"I had one or two patients who were really distressed. [The patients asked:] 'Is my arm broken or isn't it broken?' And then I actually took them to the monitor and showed them the X-ray and asked them if they can see something. They would say, 'Is it broken there?' Then I 
would say, 'Yes, so be careful with your arm.' ... I think it helps the patient then to get some clarity ... just to help him to know, okay, my worst fears have been confirmed; it is broken" (FGRAD).

Some radiographers expressed reluctance to communicate with patients about imaging results because they had not received adequate training in how to deal with patient responses, even though they recognized the potential benefit of such information for the patient.

"We [radiographers] don't learn how they're going to react and how we're going to react to how they react. So I think that is one of the main reasons we shouldn't be telling them. But at the same time I really feel that the more patients don't know what's going on, the more intimidated and afraid they feel. But often if I see people that you say, it is broken, the doctor will tell you further and you can immediately see them accept the fact. So it is a bit of a difficult situation" (FGRAD).

The dilemma between respecting and addressing patient concerns and respecting medical practitioner professional boundaries in which radiographers sometimes find themselves is aptly illustrated in the following case of a radiographer conducting a ward chest radiographic investigation:

"I didn't really know what to do. I was in the paediatric ward and it was a seven-year old boy ... the mother helped me with the child. Afterwards she looked at the X-rays as I was busy annotating on the image. She asked me why his heart was so big. I knew it was big, but I am not allowed to say because it might be pathology and she had me in an awkward situation because she can see there is something wrong. What should I tell her now? So I just told her, 'Yes, children's hearts are bigger than ours. You have to consult with your doctor. He knows what he saw in your boy. He was there; he listened to the heart and the lungs, so he knows better than I do. I just took the picture. I have no history, so rather speak to your doctor.' She immediately knew maybe with my explanation there might be something wrong but she understood after I explained. She understood I can't tell her anything more” (FGRAD).

Similar to radiographers, professional nurses were also aware of their restricted role in disclosing the results of diagnostic imaging investigations. However, they were of the opinion that they could fill communication gaps between medical practitioners and patients by explaining findings and clarifying the content of radiologic reports in lay language.

"The doctors come here [to the ward]. They check on the machine and on that light [viewing box] and then they discuss that among themselves; the x-ray and what they are going to do ... but the patient, they don't know. They don't go to the patient and tell them that" (FGNP).

"Patients do tend to ask questions, so there have been patients who have come to me with their x-ray reports and asked me to explain in Afrikaans or English what the doctor has written there to interpret the report for them" (IINP).

However, nurses recognized the limitations of their role as educators as a result of their limited knowledge and skills to interpret radiographic images and radiological reports.

"I think it will be good that they [the doctors] inform us and train us what they see" (FGNP).

"If we can be able to read the findings, we will be able to explain the findings, from there explain to the patient that they have done this. Usually most patients they are illiterate. So 
then we need to tell them the photo that they took, they found that there is a crack in your bone or ... what they took of your lungs, there is this cloudy appearance. We also need to be knowledgeable about explaining the results, though we know it's the duty of the doctors because they are the ones who diagnose" (FGNP).

\section{Theme 3: Provider-patient Communication-What Does the Patient Ultimately Experience, Know, and Understand?}

After a diagnostic imaging investigation, there is inevitably some interaction between the referring clinician and the patient regarding the results of the investigation. In our study, the interaction took place with and sometimes without images being shown to the patient. In some instances in which more than one medical practitioner was responsible for the patient, each provider conveyed a diagnostic message based on his or her own interpretation. In other instances, there was no clear diagnosis communication between the medical practitioner and patient as the patient moved to and fro between the imaging and referring departments. No patient participant requested to see any radiologic report or initiated communication about their imaging results although some participants expressed a desire for better communication of imaging results in their exit interviews.

The inadequate communication skills of some medical practitioners may have a significantly negative effect on the chain of explanation and communication with the patient as well as on the patient's perceptions and interpretations of the diagnostic investigation results. The importance of appropriate communication skills when medical practitioners have to share diagnostic information with patients regarding the presence of a serious medical condition is illustrated in the following case:

"I went to the sonar department for an abdominal sonar. While I was lying on the bed the one doctor was this side, the other doctor was [that] side. They are doing the scan ... and the doctor said, 'Oh, that's cancer.' I almost died on that table that day. I mean, really, I almost had a heart attack. Just so blunt- 'It's cancer'. I mean, that is not the way to do it. Even if it was cancer, he should have discussed it ... then come and tell me in a proper way. I was so shocked that day" (FGNP).

The importance of clear, unambiguous, and mutually consistent diagnostic messages is especially important in cases in which more than one medical professional is attending to the same patient. The importance of consistent messages is illustrated in the case of a boy admitted to a ward with a fractured femur. Conflicting diagnostic messages to his mother by a medical officer [X], an orthopaedic registrar [Y], and a medical specialist [Z] resulted in significant confusion.

"They told me two days ago my child's bone is not growing. The x-rays show it's not growing at all, this doctor [medical officer X] has told me so. And now yesterday they told me, no, but the bone is growing. Now how do you explain that? The one day they tell you there is no difference - he's been lying here for one month — and the next day the doctor [registrar Y] says the bone is all right; it is starting to grow ... I don't know, because the other doctor [Y] knows; X only came afterwards. So the other doctor [Y] who is higher than X, I think she is a specialist; she is learning for orthopaedics. Then he [specialist Z] told me they looked at the $\mathrm{X}$-rays well ... then he [Z] told me the bone is busy growing, bone formation, but not quite as it should be $100 \%$. So how did they see it if that doctor $\mathrm{X}$ had said the bone is not growing? 
... I don't know what has happened there. Because the one doctor says this and the other says that. So you are so confused. ... My head is so confused" (PI).

In summary, we observed in our study some cases in which patients had not received any clear information from any health care provider regarding the diagnostic results of their x-ray investigations. Also, the patients in our study were largely inactive communication participants and tended to refrain from requesting clarifications from the health care providers. One radiology registrar summarized the situation as follows:

"Actually in terms of x-rays or scans, our department is lacking if that's the perception of patients [to be informed on the radiological results]. At the moment we just do the report and we tell them, 'Don't worry, it's on the system. The doctor will check it up. So just go see the doctor.' That means they don't know. They don't see the report. They don't see the X-rays. They don't see anything. It's like a big secret-take the x-rays, put it into an envelope and you stick a letter on the [envelope] - 'Confidential', do not open or whatever. And they think they're not allowed to open it. Obviously then it's like they don't know what's in there. And they take it to the doctor. And it's stressful for them. So I think that is somewhere we're lacking in the system; our system is like that" (FGRADL).

This is how a medical practitioner reported on the same issue.

"I have seen patients they have been through the whole system. They come back and you ask them [what has happened]. 'Yes, they took X-rays. I had an accident. ... They never told me what was wrong with it.' ... 'No, I don't know [if I have a fracture]. They never told me.' So there is cases where it happens like that" (FGMP).

\section{Discussion}

The findings of this study provide insight into the communication processes regarding diagnostic imaging investigation results from a multiprovider perspective and a patient perspective. In this context, various ethical issues and controversies need to be considered, especially those that might result in conflict between radiologists and medical practitioners, between medical providers in the same profession, between radiographers and patients, and between nurses and patients [17]. Although all the health care providers in this study concurred that the communication of results was primarily the responsibility of the medical practitioner [18] , nonmedical providers such as the nurses and radiographers also articulated their unique roles and responsibilities related to imparting the results of diagnostic imaging investigations.

The patients in our study were often curious about the diagnostic results, but very few questioned the medical providers (medical practitioners, specialists, radiologists, and radiology registrars) about their results, possibly because of the diverse language profile of the patients served by the hospital complex where the study took place. Some patient participants would have liked to have received better communication of imaging results but were unfamiliar with the practice of requesting a radiologic report. Studies from other countries reported on patients' preference for getting their results from the radiologist immediately after the diagnostic imaging examinations [8 18] . According to Bazzocchi [3] , this preference is linked to current trends of patients being more aware and better informed about medical issues than before. As such, this consumerist trend has significant implications 
for various levels of radiologic training and practice in terms of work organization and legal and ethical matters [3 6] .

The radiologists in our study were reluctant to accept the responsibilities of direct patient communication because conveying imaging investigation results had not been considered a part of their roles in the past [4]. This reluctance might be linked to radiologists' expressed need for formal training in effective communication skills [1 18], specifically with regard to establishing an attentive relationship with a patient, sharing clinical information, and treating patients with empathy and respect within a framework of patient rights [19] . Furthermore, Ortega and Garciá [1] hold that effective communication skills and attitudes in a health care context require changing from a focus on the necessities of medical professionals to those centering on patient rights and needs. A recent survey by the European Society of Radiology on patient communication, confidentiality, and consent found that routine practice varied across Europe [20], whereas the Radiological Society of South Africa's code of conduct states that patients may directly request their imaging results or a radiology report from the radiologist "unless there is a compelling reason to believe that information contained in the record will result in substantial harm to the patient or others and/or the law prohibits disclosure" [21] . In the public health care sector in South Africa, the radiologic report is not routinely made available to the patient.

During general radiographic examinations and some that are more specialized (eg, computed tomography), the patient does not directly interact with the radiologist but only with the nonmedical health care provider [3] . In these situations the radiographers act cautiously in being truthful and compassionate, with a focus on the safety of the patient [22] . Nurses could play a significant role in bridging the communication gap between medical providers and patients, which Ortega and Garciá [1] refer to as the "humane" (p. 472) aspect of radiologic care. The common focus is the best interest of the patient. However, communication of imaging results to the patient remains fragmented between different health care providers, with no one provider having an overview of what has been communicated in the various health care service contexts. Our study found that evidence of communication "seamlessness" [8] was very sparse, and very few patients received adequate information at various points of service care; more often patients were uncertain or not informed at all.

This study was a first attempt to investigate and describe the multiprovider communication of diagnostic imaging results to patients in a South African public health care setting. Because the study was conducted qualitatively with a small number of participants in one hospital complex, no claims are made about generalising the findings to other settings although the findings may resonate with some readers and could inform the design of similar studies in the private health care sector or in other countries. A further limitation was the unpredictability of the patient cases recruited through convenience sampling, and who would be referred for a radiologic opinion or not. This could have limited the scope of the study, although data collection continued until data saturation was reached and no new insights emerged. The fact that patient participants did not request their radiologic reports nor initiate communication about their imaging results may have limited the researchers' understanding of all the possible patient reactions regarding the communication of results. With regard to process, communication, and interaction, some health care providers may have done or said the "right" thing because of the presence of a researcher with each patient. However, this potential limitation did provide the opportunity for further exploration in the focus group interviews. 
To make further recommendations regarding optimal ways of conveying radiologic results in South African public hospitals, the following is needed in further studies: exploration of existing protocols that may include references to the communication of results; analysis of the accuracy of information provided to patients; further focus on patients' engagement with radiologic reports; inclusion of more health facilities with a larger geographic spread, a broader spectrum of patients (eg, ward patients, not only day patients); and more provider participants.

Further research is also justified on the role of nonmedical providers, especially radiographers and nurses, in the context of ethical and moral obligation toward patients and the professional boundaries stipulated in their scopes of practice. Feasibility studies to assess the impact on the medical encounter where nurses and/or radiographers convey the message of the outcomes could be conducted. Studies should not only focus on the communication process and content but also on the multiprovider health care system's approach to keep patients adequately informed during their journey through the system, as well as on strategies to ensure patient comprehension of their diagnostic imaging results in relation to their condition. Lastly, our study suggests a need to design and implement continuous professional development programs that focus on effective provider-patient communication skills regarding diagnostic imaging results within the South African public health care system.

\section{Conclusion}

The findings from this study provide a bird's-eye view of the disclosure of imaging results by medical- and nonmedical health care providers, with the exception of clerks. All professional groups referred to the ideal of the referring clinician being the "carrier of the message," but all alluded to the challenges they had experienced in this regard. We found some similarities with findings from other studies in terms of nonmedical providers' ability to communicate certain types of information regarding imaging results. On the one hand, the communication context raises several ethical dilemmas, especially when nonmedical health care providers lack skills and competencies to effectively communicate imaging results. On the other hand, our study shows how nonmedical providers could play a positive role in benefiting the patient, especially when their actions are directly in the interest of the patient.

\section{Acknowledgments}

The authors wish to thank all the colleagues and patients who contributed to the study. A special word of thanks to Barbara English (Office of the Deputy Dean: Research, Faculty of Health Sciences, University of Pretoria), who provided editorial support.

The authors declare no conflicts of interest. No funding was received for this work.

\section{References}

[1] Ortega, D., and Garciá, C. (2006). Communication between radiologists and patients: unsolved issues. J Am Coll Radiol 3(6), pp. 472-477.

[2] Crotty, B., Mostaghimi, A., and Landon, B. (2013). Preparing residents for future practice: report of a curriculum for electronic patient-doctor communication. Postgrad Med J 89(1056), 554-559. 
[3] Bazzocchi, M. (2012). Doctor-patient communication in radiology: a great opportunity for future. radiology. Radiol Med 117, 339-353.

[4] Safdar, N., Shet, N., Bulas, D., and Knight, N. (2011). Handsoffs between radiologists and patients: threat or opportunity. J Am Coll Radiol 8(12), 853-857.

[5] Amber, I., and Fiester, A. (2013). Communicating findings: a justification and framework for direct radiologic disclosure to patients. AJR Am J Roentgenol 200, 586-591.

[6] Berlin, L. (2002). Communicating findings of radiologic examinations: whither goest the radiologist's duty? AJR Am J Roentgenol 178(4), 809-815.

[7] Reiner, B. (2013). Strategies for radiology reporting and communication. Part 2: using visual imagery for enhanced and standardized communication. J Digit Imaging 26, 838-842.

[8] Mathers, S., McKenzie, G., and Robertson, E. (2013). 'It was daunting': experience of women with a diagnosis of breast cancer attending for breast imaging. Radiography 19(2), 156-863.

[9] Smith, S., and Gunderman, R. (2010). Should we inform patients of radiology results? Radiol Med 255(2), 317-321.

[10] Reiner, B. (2013). Strategies for radiology reporting and communication. Part 1: challenges and heightened expectations. J Digit Imaging 26, 610-613.

[11] Ellenbogen, P.H. (2008). The radiologist assistant: best new thing since sliced bread or Trojan horse? Radiology 248(1), 4-7.

[12] Giuse, D. (2003). Supporting communication in an integrated patient record system. AMIA Annu Symp Proc 2003, 1065, Available at: http://

www.ncbi.nlm.nih.gov/pmc/articles/PMC1480157/pdf/amia2003_1065.pdf. Accessed 20 Jan 2014. [13] Pahade, J., Couto, C., Davis, R., Patel, P., Siewert, B., and Rosen, M. (2012). Reviewing imaging examination results with a radiologist immediately after study completion: patient preferences and assessment of feasibility in an academic department. AJR Am J Roentgenol 199, 844851.

[14] Berlin, L. (2009). Communicating results of all outpatient radiologic examinations directly to patients: the time has come. AJR Am J Roentgenol 192(3), 571-573.

[15] Etheredge, H. (2011). Rethinking responsibility in radiography: some ethical issues in South Africa. SA J Radiol 15(1), 10-13.

[16] Green, J., and Thorogood ,N. (2009). Qualitative methods for health research. Los Angeles London New Delhi Singapore Washington DC: Sage.

[17] Gruppetta, E. (2009). Ethical issues for radiographers: general observations and a pilot qualitative study. Radiat Prot Dosimetry 135(2), 88-89.

[18] Sasson, J., Zand, T., and Lown, B. (2008). Communication in the mammography suite: implications for practice and training. Acad Radiol 15(4), 417-424.

[19] Olivier, L., Leclère, J., Dolbeault, S., and Neuenschwander, S. (2005). Doctor-patient relationship in oncologic radiology. Cancer Imaging 11(5), S83-S88.

[20] European Society of Radiology (ESR) (2013). Patient communication, confidentiality and consent: radiology policy and practice in Europe: a survey by the European Society of Radiology. Insights Imaging 4, 153-156.

[21] Radiological Society of South Africa. The Radiological Society of South Africa Code of Conduct — confidentiality and access to records; (p.4 of 16). January 2002. Available at: INTER REF: http://rssa.co.za/the-radiological-society-of-south-africa-code-of-conduct/page-4.html. Accessed 17 April 2014.

[22] Andersson, B., Christensson, L., Jakobsson, U., Fridlund, B., and Broström, A. (2012). Radiographers' self-assessed level and use of competencies - a national survey. Insights Imaging 3, 635-645. 